\title{
Acquisition of data at multiple gains within a single thermal melt experiment using the Rotor-Gene Q instrument
}

\author{
Sai Hari A Gandham¹, David E Volk ${ }^{1,2}$ and David G Gorenstein ${ }^{1,2^{*}}$
}

\begin{abstract}
Background: Rotor-Gene Q instrument was used to perform high-resolution protein thermal melt studies to characterize protein-small-molecule interaction. Fluorescent dye (1-anilino-8-naphthalenesulfonate (1,8-ANS)) is used as a reporter of protein unfolding to measure the protein melting temperature $\left(T_{m}\right)$. Variations in the fluorescence yield upon titration of small molecules with the protein resulted in poor melting curves at low gain while a high gain setting caused signal saturation leading to data loss.
\end{abstract}

Findings: Acquisition of data at multiple gains within a single experiment provided high-quality data for samples with both low and high fluorescence yields. The melting temperatures were measured for all the samples in one run, while avoiding loss of data due to signal saturation. This method was successfully used to measure the binding constant by titration of a small-molecule ligand with the target protein.

Conclusion: Protein thermal melt experiments using the Rotor-Gene Q instrument have been made feasible for samples that show variations in fluorescence yield. Furthermore, since protein melting is irreversible, using multiple gains in the same experiment prevented loss of sample and saved gain optimization time.

Keywords: Thermal stability; Protein melting temperature; Rotor-Gene Q; Fluorescence yield; Gain optimization; Multiple-gain protocol; Small-molecule binding

\section{Introduction}

Protein thermal melt (PTM) experiments are gaining importance to study thermodynamic stability of a protein by measuring their protein melting temperature $\left(T_{\mathrm{m}}\right)$. A change in $T_{\mathrm{m}}$ upon binding of a small-molecule ligand to target protein enables this technique to be extended for high-throughput screening and characterization of binding (Pantoliano et al. 2001; Matulis et al. 2005). This label-free screening method requires no modification to protein or ligand. Further, PTM experiment uses small sample volume of at least $10 \mu \mathrm{l}$ containing low amount of protein $(10 \mu \mathrm{M})$ and a fluorescent reporter dye like SYPRO-Orange (SO) or 1-anilino-8-naphthalenesulfonate (1,8-ANS). These dyes have low fluorescence intensities when there is no interaction with protein. As protein unfolds with increasing temperature, the dye molecules interact with the protein's hydrophobic interior and show an increase in their fluorescence intensity thus acting as a reporter of protein unfolding. This helps to measure the stability of protein $\left(T_{\mathrm{m}}\right)$ in the presence and absence of a small-molecule compound to determine the differential shift in protein stability $\left(\Delta T_{\mathrm{m}}\right)$ upon compound binding. This technique and its theoretical principles are well documented (Lo et al. 2004; Cimmperman et al. 2008; Zhang and Monsma 2010). We utilized a conventional real-time PCR instrument called Rotor-Gene Q (QIAGEN, Inc., Hilden, Germany) which is ideal for performing high-resolution

\footnotetext{
* Correspondence: David.G.Gorenstein@uth.tmc.edu

${ }^{1}$ Center for Proteomics and Systems Biology, Brown Foundation Institute of Molecular Medicine for the Prevention of Human Diseases, Houston, TX 77030, USA

${ }^{2}$ Department of Nanomedicine and Biomedical Engineering, The University of Texas Health Science Center, Houston, TX 77030, USA
} 


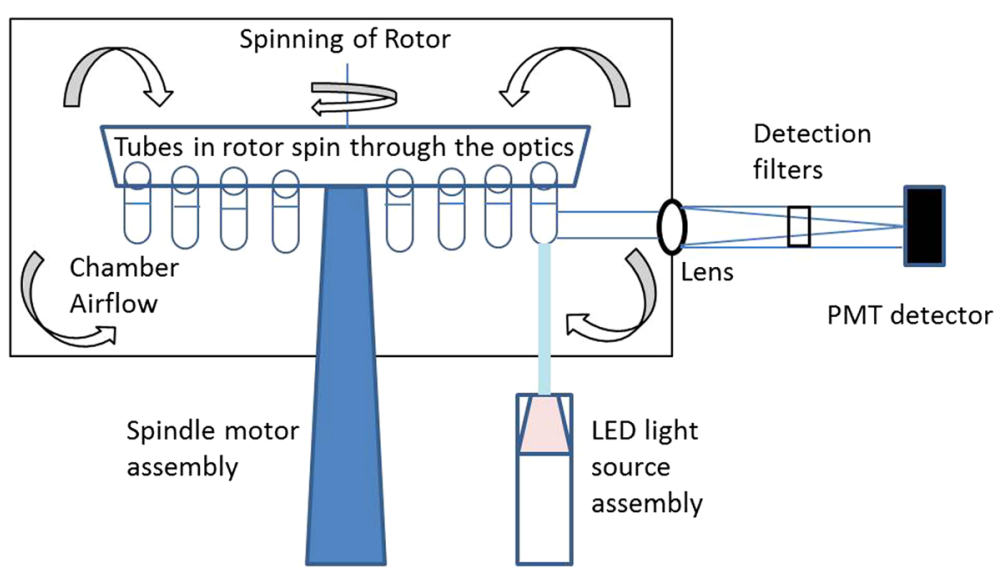

Figure 1 Schematic illustration for the working of Rotor-Gene $\mathbf{Q}$ instrument is shown. The samples in the optically clear PCR tubes spin past the optics while the LED light excites the sample and the PMT detector detects the fluorescence emission from each sample. The airflow in the chamber maintains uniform temperature across all samples.

melting of nucleic acids and protein because of its unique rotating sample holder that provides uniform temperature across all samples. A schematic of the Rotor-Gene $\mathrm{Q}$ instrument cross-sectional view is provided to show the excitation and emission light paths and the position of the samples to enable rapid highthroughput and precise detection of fluorescence. The excitation and emission wavelength pairs are set up before the start of experiment to choose the right LED light source and the detection filter. The samples in the rotary holder (interchangeable for 36 or 100 samples) spin at $400 \mathrm{rpm}$ in an enclosed chamber that allows precise temperature control (Figure 1). Also, the flexibility of Rotor-Gene Q for using several excitation and emission filter pair combinations in a single run allows for monitoring a wide array of samples using different dyes in the same experiment (Köppel et al. 2009). The major drawback that we found was with choosing the gain for the detector that has to be set at a fixed value before starting the experiment. Several gain optimization runs were needed to choose the right signal intensity for a given concentration of protein and buffer system used. In our case of small-molecule compound screening, a high gain setting caused saturation of fluorescence signal resulting in loss of data for high fluorescence yield samples while a low level of gain does not provide sufficient signal to observe the melting transition for low fluorescence yield samples (Figure 2) to accurately measure the protein stability.

\section{Findings}

By choosing the same excitation and emission filter pair (excitation wavelength of $365 \mathrm{~nm}$ and emission wavelength of $460 \mathrm{~nm}$ for ANS dye) in several channels and assigning different gains for each channel,
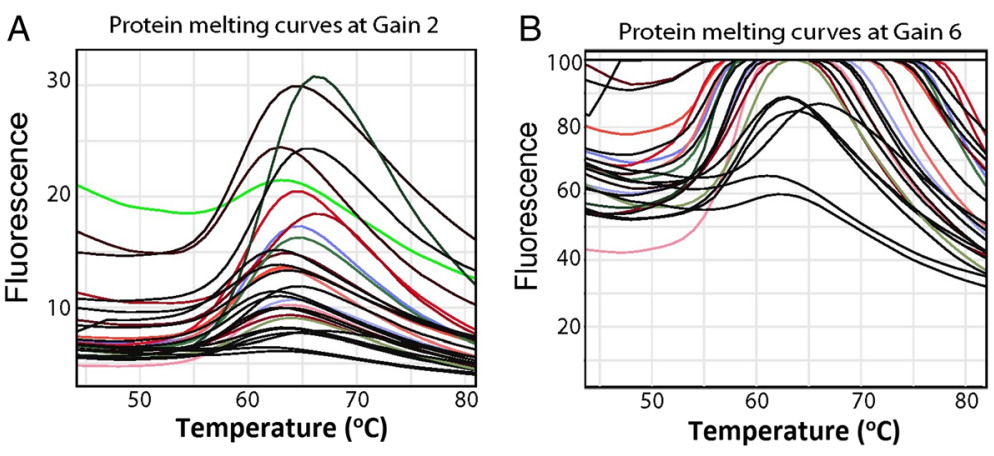

Figure 2 Fluorescence melting curves at gains 2 and 6 . (A) The fluorescence melting curves for the ten compounds $\mathrm{C} 1$ to $\mathrm{C} 10$ at gain 2 are shown. It was optimal for most samples that had relatively higher fluorescence yield. (B) Melting curves at gain 6 show optimal melting transition for samples with low fluorescence yield while samples with high fluorescence yield showed saturation of fluorescence intensity, and hence, their $\Delta T_{m}$ could not be calculated at this gain setting. 
Table $1 \Delta T_{m}$ of protein for ten compounds (C1 to C10)

\begin{tabular}{|c|c|c|c|c|c|c|}
\hline \multirow{2}{*}{$\begin{array}{l}\text { Concentration of compounds } \\
\text { C1 to C10 (mM) }\end{array}$} & \multicolumn{5}{|c|}{ The values of $\Delta T_{\mathrm{m}}$ at different gains used in the same experimental run $\left({ }^{\circ} \mathrm{C}\right)$} & \multirow[t]{2}{*}{ Average $\Delta T_{\mathrm{m}}\left({ }^{\circ} \mathrm{C}\right)$} \\
\hline & Gain -2 & Gain 0 & Gain 2 & Gain 4 & Gain 6 & \\
\hline 0.5 & 0.83 & 0.93 & 0.93 & 0.63 & - & $0.82 \pm 0.14$ \\
\hline C1 & 1.13 & 1.63 & 1.43 & - & - & $1.39 \pm 0.25$ \\
\hline 5 & 1.63 & 2.13 & & - & - & $1.87 \pm 0.35$ \\
\hline 0.5 & 0.83 & 1.33 & 1.13 & 0.93 & - & $1.05 \pm 0.22$ \\
\hline C2 & 1.13 & 1.63 & 1.63 & 1.33 & - & $1.42 \pm 0.24$ \\
\hline 5 & 1.13 & 1.63 & 1.83 & & - & $1.52 \pm 0.36$ \\
\hline 0.5 & 0.33 & 0.83 & 0.63 & 0.63 & - & $0.60 \pm 0.21$ \\
\hline C3 & -0.08 & 0.33 & 0.13 & 0.13 & - & $0.12 \pm 0.16$ \\
\hline 5 & 0.43 & 0.33 & 0.43 & 0.13 & - & $0.32 \pm 0.14$ \\
\hline 0.5 & 0.63 & 1.13 & 1.33 & 0.93 & - & $1.00 \pm 0.30$ \\
\hline C4 & 2.93 & 3.63 & 3.43 & 3.13 & - & $3.27 \pm 0.31$ \\
\hline 5 & -0.08 & 0.43 & 0.63 & & - & $0.32 \pm 0.36$ \\
\hline 0.5 & 0.43 & 0.63 & 0.63 & 0.43 & - & $0.52 \pm 0.12$ \\
\hline C5 & -0.18 & 0.13 & 0.13 & -0.18 & - & $-0.03 \pm 0.17$ \\
\hline 5 & 0.33 & 0.63 & 0.83 & - & - & $0.59 \pm 0.25$ \\
\hline 0.5 & 0.63 & 0.83 & 0.63 & 0.33 & - & $0.60 \pm 0.21$ \\
\hline C6 & 0.63 & 0.83 & 0.63 & 0.33 & 0.33 & $0.55 \pm 0.22$ \\
\hline 5 & 0.33 & 0.33 & 0.13 & -0.08 & -0.18 & $0.11 \pm 0.23$ \\
\hline 0.5 & 0.43 & 1.43 & 0.93 & - & - & $0.93 \pm 0.05$ \\
\hline C7 & -0.18 & 0.13 & - & - & - & $-0.03 \pm 0.21$ \\
\hline 5 & - & - & - & - & - & - \\
\hline 0.5 & 1.13 & 1.43 & 1.13 & 0.83 & 0.63 & $1.03 \pm 0.31$ \\
\hline C8 & 1.13 & 1.63 & 1.63 & 1.33 & - & $1.43 \pm 0.24$ \\
\hline 5 & 2.43 & 2.83 & 3.13 & & - & $2.79 \pm 0.35$ \\
\hline 0.5 & - & 0.33 & 0.13 & -0.38 & -0.38 & $-0.08 \pm 0.36$ \\
\hline C9 & - & 1.33 & 1.13 & 0.93 & 0.83 & $1.05 \pm 0.22$ \\
\hline 5 & 2.63 & 3.63 & 3.63 & 3.13 & 3.13 & $3.23 \pm 0.42$ \\
\hline 0.5 & 0.43 & 0.83 & 0.63 & 0.43 & - & $0.58 \pm 0.19$ \\
\hline C10 & 1.13 & 1.63 & 1.43 & 1.13 & - & $1.33 \pm 0.24$ \\
\hline 5 & 1.83 & 2.33 & 2.33 & 1.93 & - & $2.10 \pm 0.26$ \\
\hline
\end{tabular}

Hyphen indicates samples that did not show fluorescence melting signal above threshold noise level or resulted in signal saturation (data loss) due to high fluorescence intensity. The $\Delta T_{\mathrm{m}}$ of protein was measured for the ten compounds $\mathrm{C} 1$ to $\mathrm{C} 10$ at three concentrations $(0.5,2$, and $5 \mathrm{mM})$ at five levels of gain set within a single experimental run. $T_{\mathrm{m}}$ of the protein $\left(T_{\mathrm{m}}\right.$ ref $)=58.4 \pm 0.2^{\circ} \mathrm{C}$. 


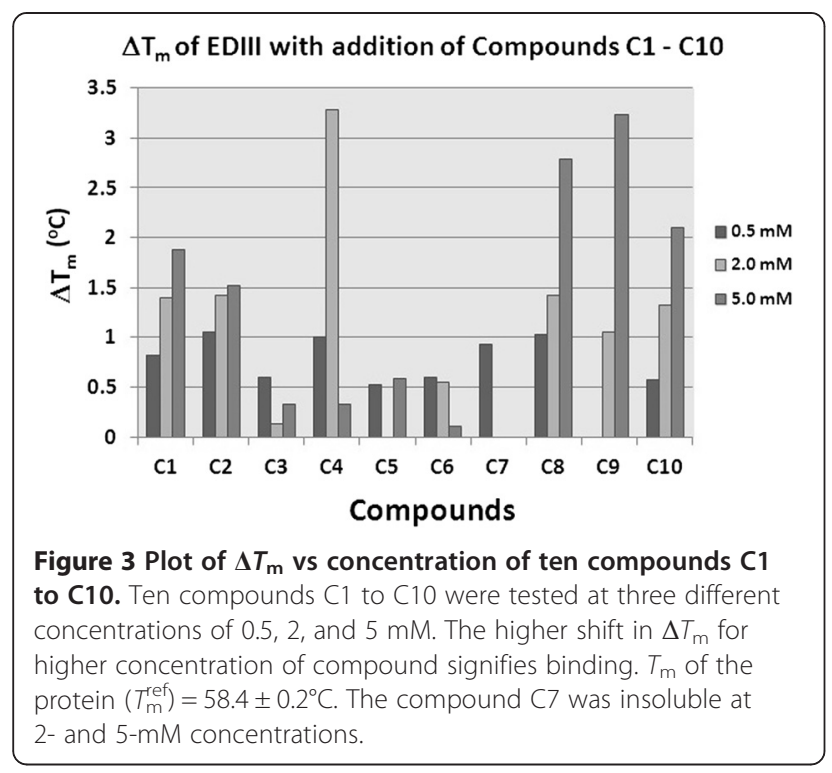

protein unfolding was monitored at multiple gains in a single experiment. This enabled the monitoring of samples that had different yields of fluorescence intensity in the same experiment without significant increase in the run time. This method is novel and to the best of our knowledge, it has not been used previously. The use of the ANS dye with the Rotor-Gene Q instrument has been demonstrated to work with our model protein to study binding of small-molecule compounds by using different levels of gain in a single PTM experiment.

\section{Model system used}

Recombinantly expressed and purified envelope protein domain III (EDIII) from dengue virus (serotype-2 WT strain 11608) was used at a concentration of $10 \mu \mathrm{M}$ in a total sample volume of $10 \mu \mathrm{l}$. The structure of EDIII has seven beta strands that form a beta barrel. The loops at the top contain the critical neutralizing epitopes, and thus, this protein is important for the development of vaccines and therapeutics targeting the dengue virus. Optimization for maximum fluorescence signal and melting transition was performed using various buffer systems at different concentrations of protein, salt, and ANS dye. PBS buffer $(\times 0.5$ containing $5.95 \mathrm{mM}$ phosphates, $68.5 \mathrm{mM} \mathrm{NaCl}, 1.35 \mathrm{mM}$ $\mathrm{KCl}$, at $\mathrm{pH}$ 7.4) and $50 \mu \mathrm{M}$ ANS provided the optimal fluorescence melting transition for $10 \mu \mathrm{M}$ protein, and the protein melting temperature of the protein $\left(T_{\mathrm{m}}{ }^{\text {ref }}\right)$ was determined as $58.4 \pm 0.2^{\circ} \mathrm{C}$. Computational methods (data not shown) were used to identify several smallmolecule compounds that showed possible interactions with our protein. Ten compounds ( $\mathrm{C} 1$ to $\mathrm{C} 10)$ from this set were tested at three different concentrations for each $(0.5,2$, and $5 \mathrm{mM})$ to obtain the protein melting curves and the first derivative of melting curves $(\mathrm{dF} / \mathrm{dT})$ for different levels of gain.

\section{Results}

Melting temperatures were obtained for the protein without the compounds $\left(T_{\mathrm{m}}{ }^{\text {ref }}\right)$ and with the compounds $\left(T_{\mathrm{m}}{ }^{\text {com }}\right)$ using their corresponding optimal melting curves. The protein melting temperature values were measured by the Rotor-Gene Q-Pure Detection software version 2.0.2 (Build 4). The differences in melting temperatures $\left(\Delta T_{\mathrm{m}}=T_{\mathrm{m}}{ }^{\text {com }}-T_{\mathrm{m}}{ }^{\text {ref }}\right)$ were calculated (Table 1) where an increase in $\Delta T_{\mathrm{m}}$ with increasing concentration of compound signified binding (Figure 3). Based on this initial testing, compound 8 (C8) was found to bind the protein in a dosedependent manner, among several others. A titration

Table 2 The $\Delta T_{m}$ of protein at various concentrations of $\mathrm{C} 8$

\begin{tabular}{|c|c|c|c|c|c|c|c|c|c|c|c|c|c|}
\hline \multirow[t]{2}{*}{ [C8] mM } & \multicolumn{12}{|c|}{$\Delta T_{\mathrm{m}}$ at different levels of gain $\left({ }^{\circ} \mathrm{C}\right)$} & \multirow{2}{*}{$\begin{array}{l}\text { Average } \\
\Delta T_{\mathrm{m}}\left({ }^{\circ} \mathrm{C}\right)\end{array}$} \\
\hline & -2 & -1 & 0 & 1 & 1.3 & 1.7 & 2 & 2.3 & 3 & 3.5 & 4 & 5 & \\
\hline $0.25^{\mathrm{a}}$ & - & 1.7 & 1.2 & 2.2 & 1.9 & 1.2 & 0.9 & 1 & 0.7 & 1.5 & 1 & 0.9 & $1.29 \pm 0.45$ \\
\hline 0.75 & 1.7 & 2.7 & 2.9 & 2.7 & 2.7 & 2.7 & 1.7 & 2.2 & 1.7 & 1.5 & 1.7 & 2 & $2.22 \pm 0.50$ \\
\hline 1 & 2.9 & 3 & 2.9 & 3 & 2.9 & 2.9 & 2.4 & 2.2 & 2.2 & 2.2 & 2.2 & 2.2 & $2.55 \pm 0.36$ \\
\hline 1.5 & 2.7 & 3 & 3.5 & 3.2 & 2.7 & 2.9 & 2.7 & 2.7 & 2.7 & 2.7 & 2.5 & 2.5 & $2.82 \pm 0.28$ \\
\hline 2 & 3.2 & 3.4 & 3.7 & 3.7 & 3.4 & 3.2 & 3.2 & 3.2 & 3 & 3 & 3.2 & 3 & $3.27 \pm 0.23$ \\
\hline 2.5 & 3 & 3.4 & 3.7 & 3.5 & 3.4 & 3.2 & 3.2 & 3 & 2.9 & 3 & 2.9 & 2.9 & $3.19 \pm 0.26$ \\
\hline 3 & 3.2 & 3.5 & 3.7 & 3.7 & 3.4 & 3.4 & 3.2 & 3.2 & 3.2 & 3.2 & 3 & 3 & $3.31 \pm 0.23$ \\
\hline 3.5 & 3 & 3.7 & 3.7 & 3.7 & 3.5 & 3.4 & 3.4 & 3.2 & 3.2 & 3.2 & 3.2 & 3.2 & $3.40 \pm 0.23$ \\
\hline
\end{tabular}

${ }^{\mathrm{a}} T_{\mathrm{m}}$ could not be calculated for -2 gain due to low fluorescence signal, and the melting curves were below threshold. $\Delta T_{\mathrm{m}}$ of protein for ten compounds ( $\mathrm{C} 1$ to (10). The $\Delta T_{\mathrm{m}}$ of protein was measured at different gain levels set within the same experimental run that were used to determine the binding affinity; $T_{\mathrm{m}}$ of the protein $\left(T_{\mathrm{m}}^{\mathrm{ref}}\right)=58.4 \pm 0.2^{\circ} \mathrm{C}$. The $\Delta T_{\mathrm{m}}$ were calculated by the Rotor-Gene Q-Pure Detection software version 2.0.2 (Build 4). 

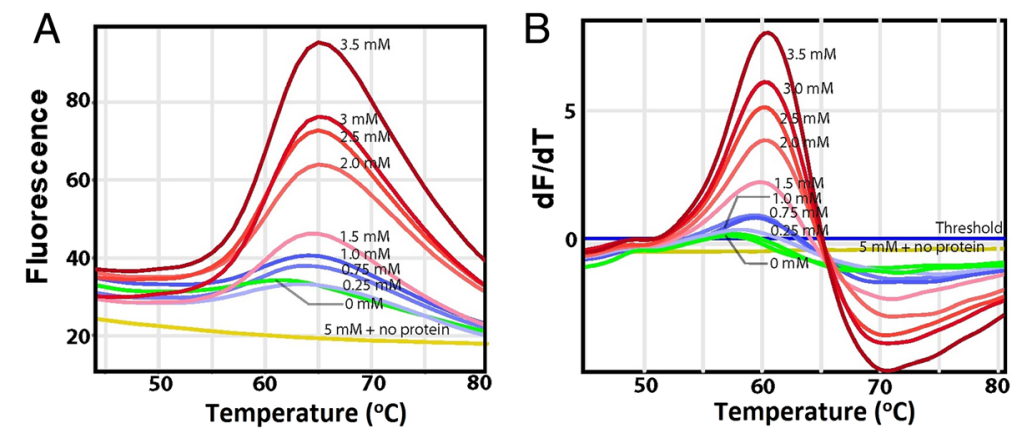

Figure 4 Titration of compound $\mathbf{8}$ with the target protein. (A) Fluorescence melting curves showing change in fluorescence intensity with increasing temperature for different concentrations of $\mathrm{C} 8$ shown in the figure. (B) First derivative of melting curves (dF/dT) is plotted and the temperature at maximum $\mathrm{dF} / \mathrm{dT}$ is the protein melting temperature $\left(T_{\mathrm{m}}\right)$. The data for gain level of 5 are shown.

experiment was performed for increasing concentrations of $\mathrm{C} 8$ from 0.25 up to $3.5 \mathrm{mM}$ to obtain melting curves and the first derivative curves at different gains to calculate the protein melting temperature and their corresponding $\Delta T_{\mathrm{m}}$ (Table 2). The fluorescence intensity data for a gain level of 5 is shown in Figure 4. The plot of $\Delta T_{\mathrm{m}}$ vs $\mathrm{C} 8$ concentration was fit using nonlinear regression equation for one-site-specific binding $\left[\Delta T_{\mathrm{m}}=\Delta T_{\mathrm{m}}(\max )^{*}[\mathrm{C} 8] /\left(K_{\mathrm{d}}+[\mathrm{C} 8]\right)\right]$ using GraphPadPrism ( $\mathrm{v}$ 5.07), and the binding affinity $\left(K_{\mathrm{d}}\right)$ was determined to be $516.2 \mu \mathrm{M}$ (Figure 5). The values of protein melting temperature that could be measured at all the different gains were used in the fit, and the variations in $\Delta T_{\mathrm{m}}$ could be observed by the error bars. The results clearly indicate that our method provides the best use of the Rotor-Gene Q instrument for optimization of gain and for performing protein melts for several samples by collecting data simultaneously at multiple gains in a single run thereby increasing the throughput.

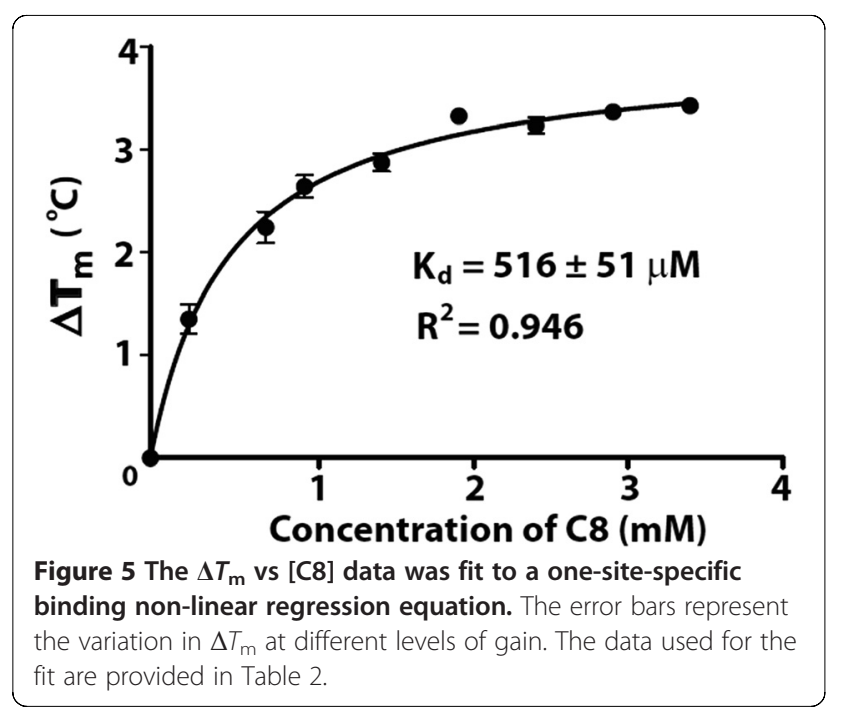

\section{Conclusion}

Optimization of gain can be a challenging task, and it is impossible to use fixed gain for samples that have varying fluorescence yields in a single experiment. Here, we have demonstrated a novel method for using the Rotor-Gene Q instrument for PTM using multiple levels of gain in the same experiment. Since PTMs are mostly irreversible, our method should help to save precious sample and time.

\section{Availability and requirements}

Project name: Rotor-Gene Q-Pure Detection v2.0.2 (Build 4)

Operating system(s): $\mathrm{PC}$

Programming language: Unknown

Other requirements: None

License: Commercially available from Qiagen

Any restrictions to use by non-academics: license needed

Abbreviations

EDIII: envelope protein domain III; PTM: protein thermal melt; $T_{m}$ : protein melting temperature.

\section{Competing interests}

The authors declare that they have no competing interests with the findings presented here. D.G.G. and the University of Texas Health Science Center at Houston have research-related financial interests in AptaMed Inc. and AM Biotechnologies LLC (Houston, TX).

\section{Authors' contributions}

SHAG performed the experiments. SHAG and DEV analyzed the data. All authors contributed to preparation of the manuscript. All authors read and approved the final manuscript.

Received: 22 August 2014 Accepted: 6 January 2015

Published online: 27 January 2015

\section{References}

Pantoliano MW, Petrella EC, Kwasnoski JD, Lobanov VS, Myslik J, Graf E, Carver T, Asel E, Springer BA, Lane P, Salemme FR (2001) High-density miniaturized thermal shift assays as a general strategy for drug discovery. J Biomol Screen 6:429-440

Matulis D, Kranz JK, Salemme FR, Todd MJ (2005) Thermodynamic stability of carbonic anhydrase: measurements of binding affinity and stoichiometry using ThermoFluor. Biochemistry 44:5258-5266 
Lo MC, Aulabaugh A, Jin G, Cowling R, Bard J, Malamas M, Ellestad G (2004) Evaluation of fluorescence-based thermal shift assays for hit identification in drug discovery. Anal Biochem 332(1):153-159

Cimmperman P, Baranauskiene L, Jachimoviciute S, Jachno J, Torresan J, Michailoviene V, Matuliene J, Sereikaite J, Bumelis V, Matulis D (2008) A quantitative model of thermal stabilization and destabilization of proteins by ligands. Biophys J 95:3222-3231

Zhang R, Monsma F (2010) Fluorescence-based thermal shift assays. Curr Opin Drug Discov Dev 13:389-402

Köppel R, Zimmerli F, Breitenmoser A (2009) Heptaplex real-time PCR for the identification and quantification of DNA from beef, pork, chicken, turkey, horse meat, sheep (mutton) and goat. Eur Food Res Technol 230:125-133

Submit your manuscript to a SpringerOpen ${ }^{\circ}$ journal and benefit from:

- Convenient online submission

- Rigorous peer review

- Immediate publication on acceptance

- Open access: articles freely available online

- High visibility within the field

- Retaining the copyright to your article

Submit your next manuscript at $\gg$ springeropen.com 